\title{
Health first, genetics second: exploring families' experiences of communicating genetic information
}

\author{
Laura E Forrest ${ }^{1,2,3}$, Lisette Curnow ${ }^{4}$, Martin B Delatycki ${ }^{2,3,4}$, Loane Skene ${ }^{5}$ and \\ MaryAnne Aitken*,1,3
}

\begin{abstract}
${ }^{1}$ Genetics Education and Health Research, Murdoch Childrens Research Institute, Royal Children's Hospital, Parkville, Victoria, Australia; ${ }^{2}$ Bruce Lefroy Centre for Genetic Health Research, Murdoch Childrens Research Institute, Royal Children's Hospital, Parkville, Victoria, Australia; ${ }^{3}$ Department of Paediatrics, The University of Melbourne, Melbourne, Victoria, Australia; ${ }^{4}$ Genetic Health Services Victoria, Royal Children's Hospital, Parkville, Victoria, Australia; ${ }^{5}$ The Melbourne Law School, The University of Melbourne, Melbourne, Victoria, Australia
\end{abstract}

Genetic information may have health and reproductive implications for the proband and their family members. The responsibility for communicating this information within families generally lies with the proband or consultand. Previous research has explored the barriers and facilitators to communication, particularly in families affected with familial cancer syndromes. This study is an exploration of families' experiences, which aims to elucidate the process of communicating genetic information in families affected with non-cancer genetic conditions. The methodology involved 12 semi-structured interviews with probands, consultands and their family members. There were six different genetic conditions present in the families: adrenoleukodystrophy $(n=3)$, cystic fibrosis $(n=3)$, fragile $X$ syndrome $(n=1)$, haemochromatosis $(n=1)$, balanced reciprocal chromosomal translocation $(n=3)$ and Robertsonian chromosomal translocation $(n=1)$. The results presented arise from two key themes, $(1)$ the diagnosis and (2) post diagnosis. The interview data illustrate that the time of the diagnosis is a traumatic experience for families and that communication stimulated by this event revolves around informing family members about the diagnosis, but not warning them of their genetic risk. Post diagnosis, the collection of information about the genetic condition and continued communication to more distant family members, often using pre-existing family communication patterns, enables the continuation of communication about the genetic condition.

European Journal of Human Genetics (2008) 16, 1329-1335; doi:10.1038/ejhg.2008.104; published online 21 May 2008

Keywords: adrenoleukodystrophy; chromosomal translocation; cystic fibrosis; family communication; fragile $\mathrm{X}$ syndrome; genetic counselling

\section{Introduction}

The diagnosis of a genetic condition rarely affects one individual in a family. The health and reproductive implications that are inherent in the diagnosis of a genetic

*Correspondence: Dr MA Aitken, Genetics Education and Health Research, Murdoch Childrens Research Institute, 10th Floor, Royal Children's Hospital, Flemington Road, Parkville 3052, Victoria, Australia.

Tel: +61 38341 6421; Fax: + 6139348 1891;

E-mail: maryanne.aitken@mcri.edu.au

Received 12 November 2007; revised 28 February 2008; accepted 17 April 2008; published online 21 May 2008 condition may also be relevant for family members. The responsibility of communicating the genetic information to family members generally lies with the diagnosed individual (proband) or, in the case of minors, with their parents (consultands). Family members largely rely on these individuals to disclose the genetic information so that they can make informed decisions about whether to explore their own risk further.

Once a genetic diagnosis has been made, individuals are generally encouraged during the genetic counselling process to communicate genetic information to their 
family members. ${ }^{1,2}$ This encouragement is widely accepted as current practice, and, in some genetic services, it may be the only guidance or support individuals receive from genetic health professionals about communicating genetic information to their family members. However, debate about the genetic health professional's role regarding the adequacy of support for families stems from ethical and medicolegal positions about possible implications for uninformed at-risk family members. ${ }^{3-5}$

The barriers and facilitators of communication of genetic information in families have been reported in the literature. First-degree family members are more frequently informed than second- or third-degree family members, ${ }^{6,7}$ gender is an influencing factor as women are more likely to communicate, $^{8}$ and social and emotional bonds between family members also encourage communication. ${ }^{9,10}$ Some other factors include pre-existing familial patterns of communication, ${ }^{11}$ the mode of inheritance of the genetic condition, ${ }^{12}$ positive family history ${ }^{13}$ and the perception of the ability to act on the genetic information. ${ }^{14}$

The literature in this area largely focuses on research into family communication about familial cancer syndromes such as hereditary breast and ovarian cancer and hereditary non-polyposis colorectal cancer with fewer publications exploring communication in families with non-cancer genetic conditions. ${ }^{15}$ The diagnosis of a familial cancer syndrome may result in a different experience of communicating genetic information to that of families with a non-cancer diagnosis. Familial cancer syndromes are often diagnosed when an individual and their family members have been affected with cancer, and, therefore, familial discussions about cancer may be more commonplace prior to diagnosis when compared with families with a noncancer genetic condition where the diagnosis often occurs unexpectedly.

The familial implications of a genetic diagnosis and associated family communication may be considered within the context of family system theory where events that affect an individual also affect the entire family system. ${ }^{16}$ Family system theory describes communication as a transactional process between family members, which underpins the family system ${ }^{17}$ and influences relationships between members. ${ }^{16}$ This theory also describes how power within relationships influences communication and is often used to achieve certain goals.

More recently, there has been a call to look beyond the factors influencing communication to further explore the process and the outcomes of communication. ${ }^{15}$ This is less commonly documented in the literature and the outcome of communication is often defined by the number of at-risk family members that contact the genetic services. ${ }^{9}$ The frequency of contact is estimated to be between 20 and $40 \%,{ }^{18,19}$ and whereas barriers and facilitators to communication are well documented, ${ }^{20-24}$ the reason at-risk family members do not contact the genetic services is largely unknown. Exploration of families' experiences may further illuminate the process of communicating genetic information and provide evidence-based information for health professionals involved in the provision of genetic services. Therefore, the aim of this study was to explore families' experiences of communicating genetic information.

\section{Methods}

Qualitative methodology was chosen for this exploratory study. Ethics approval for the researcher (LEF) to undertake semi-structured interviews with probands, consultands and their family members was granted by the Human Research Ethics Committee at the Department of Human Services Victoria (Australia) (60/05).

\section{Recruitment}

Probands and consultands were primarily recruited through Genetic Health Services Victoria (GHSV) by utilising genetic files to identify potential participants according to a set of criteria. Two of the researchers who are genetic clinicians (MBD and LC) identified 53 potential participants, who were not their own clients, had attended an appointment at GHSV between 2 and 5 years prior to recruitment, were over 18 years of age, spoke and read English, and who had been diagnosed with a genetic condition that had familial implications. Where the proband was a minor, their parents as consultands were identified as potential participants. Recruitment letters were sent to potential participants in December 2005, by the clinical geneticist who was the consultant involved in their care.

To recruit probands' family members and maintain their privacy, all probands and consultands who were interviewed were asked to pass on recruitment letters to those family members related by blood.

The project was also advertised by Cystic Fibrosis Victoria (CFV), which included information about the interviews on their web site (http://www.cfv.org.au).

For all types of recruitment, interested participants had to contact the researcher (LEF) to organise an interview.

\section{Interviews}

Interviews were conducted with eligible probands, consultands and their family members at Genetic Health Services Victoria, in the interviewee's home or over the telephone. A semi-structured interview was undertaken to provide the participants with the opportunity to describe their personal experiences, while allowing the interviewer to elicit responses about family communication. The semistructured interview included questions covering the following areas: finding out about the genetic condition, family, disclosure of information to family members and the role of genetic health services. All interviews were digitally recorded and transcribed verbatim. The interviews were anonymised by assigning participants and family 
members pseudonyms and removing identifying information. The interview data were initially independently coded into recurring ideas and themes by three researchers (LEF, MAA and LC) to reduce subjectivity. ${ }^{25}$ The coded transcripts were compared for consistency, and then one researcher (LEF) continued the analysis through an iterative process by repeatedly reading the transcripts and grouping similar ideas into themes. ${ }^{25}$ Titles were given to each theme to describe the content and similar themes were grouped into overarching themes. ${ }^{25,26}$

\section{Results}

Responses were received from seven potential participants from 53 recruitment letters, one from a family member recruitment letter and three from the CFV web site. Two participants were interviewed together, so in total 12 interviews were conducted with 11 women and 2 men. There were six different genetic conditions affecting the families of the interviewees; adrenoleukodystrophy, cystic fibrosis, fragile $\mathrm{X}$ syndrome, haemochromatosis, a balanced reciprocal chromosomal translocation and a Robertsonian translocation (Table 1).

The results from the interview data illustrate the commonalities between the participants' stories, where the diagnosis of a genetic condition was invariably a traumatic experience for families. Communication with family members about the diagnosis generally occurred immediately to inform them of the diagnosis and continued post diagnosis as more information was gathered. The immediate communication was generally not undertaken with the purpose of warning family members about their genetic risk, but instead informed family about the unexpected diagnosis and subsequent health implications; communication generated familial support during this traumatic event. To illustrate this process, the results have been divided into two overarching themes, 'the diagnosis' and 'post diagnosis'. Each group is further divided into themes and illustrated below with quotes from the interview data.

\section{The diagnosis Trauma}

The diagnosis of a genetic condition is almost always a traumatic experience for probands or in the case of minors, their parents. Many of the participants were emotional when describing the time of diagnosis and had 'flashbulb' memories ${ }^{27}$ that were imprinted from when they first were told. The health implications of the genetic condition were often described as the most difficult part of the diagnosis to come to terms with.

The emotional response The interview data provided illustrative examples of the emotional response that participants experienced at the time of diagnosis. The participants shared varied descriptions of their emotional responses, which ranged from extremely negative experiences to more positive perspectives (Box 1). One participant, Zoë, described the impact that the diagnosis had with a 'flashbulb' memory from the night she and her husband learnt their son's diagnosis.

Box 1 The emotional response

$\begin{aligned} & \text { '... that night we had cooked a roast lamb. Couldn't eat a roast } \\ & \text { lamb for another like, two years I'd say. Because we just kept } \\ & \text { thinking, that was what I was eating the night the phone call } \\ & \text { came through' } \\ & \text { Zoë, son has cystic fibrosis } \\ & \text { '...it was devastating... when you're in that state of shock; it's } \\ & \text { like grieving, like you can't think of anything' } \\ & \text { May, two sons have adrenoleukodystrophy } \\ & \text { 'the first two weeks, I just laid in bed and cried. Between the } \\ & \text { hours of } 7 \text { and } 7, \text { I got up and I was on remote control ... but as } \\ & \text { soon as the children were back in bed, I was curled up in my bed } \\ & \text { in the foetal position just thinking, this cannot be happening to } \\ & \text { my child.' } \\ & \text { Ava, son has adrenoleukodystrophy } \\ & \text { 'it was actually a feeling of great relief because I finally knew } \\ & \text { why I was losing the babies. It was something concrete. So that } \\ & \text { was really good, finding that out' } \\ & \text { Liz, has a balanced reciprocal chromosomal translocation }\end{aligned}$

Table 1 Description of participants

\begin{tabular}{ll}
\hline Name (pseudonym) & Genetic condition \\
\hline Ava & Adrenoleukodystrophy \\
May & Adrenoleukodystrophy \\
Ruby & Adrenoleukodystrophy \\
Nicole & Cystic fibrosis \\
Quentin and Bette & Cystic fibrosis \\
Zoë & Cystic fibrosis \\
Adele & Fragile X syndrome \\
Olivia & Haemochromatosis \\
Aaron & Reciprocal chromosomal translocation \\
Liz & Reciprocal chromosomal translocation \\
Yvette & Reciprocal chromosomal translocation \\
Zara & Robertsonian translocation \\
\hline
\end{tabular}


Grasping the health implications Most of the participants felt that the genetic information inherent in the conditions was of secondary importance compared with their primary concern of understanding the health and development implications that the genetic diagnosis carried (Box 2).

\section{Immediate communication}

Interview participants, adult probands or consultands in the case of minors, frequently reported telephoning their parents very quickly after learning of the diagnosis to pass on the information. Only one participant, Adele, waited until the following morning to contact her mother (Box 3).

\section{Health first, genetics second}

This data illustrate how the diagnosis of a genetic condition is often a traumatic experience that generates an emotional response and 'flashbulb' memories for families. At the time of the diagnosis, the proband or consultand may be more likely to focus primarily on the health implications rather than on the genetic inheritance of the condition. Consequently, communication during this stage is about informing family members to elicit support rather than informing them to warn them that they may also be at-risk of the genetic condition (Box 4).

\section{Post diagnosis}

\section{Gathering information}

After a diagnosis has been given, participants commonly reported searching for more information about the genetic condition (Box 5).

This common desire to know more may have equipped participants with a better understanding and knowledge of the genetic condition. This, in turn, may enhance their ability to grasp complexities and facilitate more effective communication of the genetic information to their family members.

\section{Family patterns of communication}

Despite immediate communication to close family members at the time of the diagnosis, communication to other family members continued post diagnosis. One common process was to utilise pre-existing familial patterns of communication, which often involves informing parents and asking them to inform their siblings, who will, in turn, inform their children. This method of communication often resulted in an ambiguous outcome regarding family members' awareness about the genetic information. However, Quentin, who is the family patriarch and whose granddaughter has cystic fibrosis, perceived that the responsibility of communicating to other family members lay with his daughter and son-in-law. Nevertheless, regardless of the pattern of communication, most partici-
Box 2 Grasping the health implications

'[it was] the long term outcome that was the more difficult to come to grips with'

Zoë, son has cystic fibrosis

'I was more concerned about you know, how I feel about Liam' Adele, son has fragile $\mathrm{X}$ syndrome

'...they sort of, in lay man's terms, they sort of explained it to me. It didn't sort of make it any clearer to me, because the main thing that's in your mind is, "well what does this mean for my child?"'

Zara and her son have a Robertsonian translocation

'as a scientist I sort of focused on the facts and looking at the probabilities and you know filtering through that and seeing well two thirds survive childhood so that's what I hung on to' May, two sons have adrenoleukodystrophy

Box 3 Immediate communication

'I made a phone call immediately. My father was in a very
important meeting and I called him out of that'
Nicole, daughter has cystic fibrosis
'I remember calling mum that night ... probably within the
hour, hour and a half'
Zoë, son has cystic fibrosis
$\begin{aligned} & \text { 'I rang my mum the day after we got [the diagnosis], because } \\ & \text { next morning' }\end{aligned}$
Adele, son has fragile X syndrome

Box 4 Communicating to inform, not to warn

'I told them, I mean I'm from a close family, and maybe right at that time, I was more concerned about her [daughter] health anyhow. More than worrying about my brothers and their children'

Nicole, daughter has cystic fibrosis

'you are the information bearer and you're also the mother struggling to deal with the news'

May, sons have adrenoleukodystrophy

\section{Box 5 Gathering information}

'we were still reeling with the news and we were just trying to get as much information as we could'

Adele, son has fragile $X$ syndrome

'I guess at the start, the first 12 months, we were in this quest for knowledge, we kept looking at what was there and what was out'

Zoë, son has cystic fibrosis

'we got this paper and it was the seminal paper written on ALD (adrenoleukodystrophy) in 1997 by Dr Hugo Moser and that was really good. That gave us ... that gave me the details' May, two sons have adrenoleukodystrophy 
Box 6 Family patterns of communication

'so if there's anything that needs to be communicated around the family, you know that as long as you've reached that top level, so Nanna and Pa on my mum's side, then it will filter downwards and capture everyone'

Olivia, is at high risk of haemochromatosis

'my father has told her [Liz's cousin's] father, but whether or not that information has filtered through to the cousins I don't know'

Liz, she and her son have a balanced reciprocal chromosomal translocation

'we left it to Meg and Danny [daughter and son-in-law] to ring them naturally, we didn't think it was our place to go ringing family members and extended family members'

Quentin, granddaughter has cystic fibrosis

\section{Box 7 Family members' awareness}

\begin{abstract}
'my sisters' [are] quite good, but on the other side, what used to be quite, if they've got colds they keep them away, now his mum sometimes turns up, dragging one of the sick

grandchildren because she's minding them for the day, because they're off school. And we're both saying, "what the heck did you bring ... ?" They just don't think anymore. So, it's probably bad now, that it's not at their mind, and so they don't think enough'
\end{abstract}

Zoë, son has cystic fibrosis

'she [sister] said to me the other day, "oh I know Liam's, you know, Liam's on a good day, quite mild and stuff". But we don't see her that often and when she sees Liam, might see her every couple of weeks, and when she sees Liam it's only for an hour, watching TV and he's fine. So, she doesn't see the real implications of fragile $X$... someone with fragile $X$ can be severely affected and they can have not just intellectual problems, but they can have behavioural problems, sleep problems, sensory problems, their needs can be really... yeah' Adele, son has fragile $X$ syndrome

'their son won't be tested. He's just of the opinion, "oh Dad's a carrier, I'm a carrier, so what?" And my brother just, someone told my brother at the genetic clinic that, "it's just like inheriting blue eyes". And so he says, "oh it's no big deal" ... His wife gets really upset about ... the way he brushes it off. And my father's worse probably. He says, "it's a whole lot of rubbish". He doesn't want to know about it'

Yvette, has a balanced reciprocal chromosomal translocation

'pretty much, it's Liz's problem. It's not ours. You know, that's interesting but it doesn't really affect us. None of them will have testing. Absolutely none of them are interested'

Liz, has a balanced reciprocal chromosomal translocation

pants depicted a scenario where communication continued post diagnosis to more distant family members (Box 6).

\section{Family members' awareness}

Despite participants' reports of communication in their families, many commented about their family members' lack of awareness about the genetic condition. This manifested as a poor understanding of the health implications or severity of the condition, or regarding personal risk of also carrying the genetic condition. Zoë illustrated her perception of her family's lack of awareness of her son's increased susceptibility to infections by describing occasions where sick cousins were brought around to visit. Another participant, Yvette, described her experience where, although family members were aware that they might have inherited the genetic condition, they appeared to remain unconcerned about the reproductive implications or dismissive of the genetic condition. Most of the participants had concerns about various family members' understanding in regards to the diagnosis of a genetic condition, the inherent health and reproductive implications, the severity of the genetic condition or their at-risk status (Box 7).

\section{Discussion}

The communication of genetic information in families has previously been described as a process rather than a single event. ${ }^{15,21}$ More recently, Gaff et al ${ }^{15}$ have acknowledged a need to explore the process and outcome of communication to validate or potentially extend genetic health professionals' practice in this area. The results from this exploratory study support the description that families' communication about genetic information is a process that takes place over time, and also demonstrates that the underlying focus of communication varies.

The results from the interviews illustrate that regardless of the genetic condition, the time of diagnosis is traumatic and families' focus is on the diagnosed individual and the health implications inherent in the genetic condition. Prior research has also documented that the diagnosis of a genetic condition is a traumatic experience for families. ${ }^{28-30}$ Communication is an integral part of families' coping mechanisms where supportive family members are immediately told about the diagnosis of the genetic condition to inform them and elicit support, but not to warn them of their genetic risk. These data are well supported by the literature where close family members are more likely to be informed than distant family members, ${ }^{6}$ and communication occurs rapidly after diagnosis. ${ }^{31}$ Although prior research has identified these common communication factors, the data from the current study differ, where the focus during this time is not about 'worrying about my brothers and their children' (Nicole), but instead being 'more concerned about her [daughter's] health' (Nicole).

Searching and collecting information about a condition or disease is reported as a common experience after a medical diagnosis is given. ${ }^{32}$ Many of the participants in this research reported that post diagnosis, they utilised the Internet, sought scientific articles and accessed any available texts to supplement their knowledge and understanding of the genetic condition affecting them or their children. This educative process may aid individuals when disseminating information to their family members by 
providing them with a better understanding and, therefore, stronger basis from which to explain the genetic information. $^{33}$

The use of existing familial patterns of communication, illustrated in this study by informing parents and requiring them to shoulder the responsibility of disseminating information within the family, may be explained by power within relationships that is an important element of family system theory. ${ }^{16}$ Power influences who is expected to undertake communication within families ${ }^{16}$ and may explain why some probands and consultands relinquish the responsibility of informing family members to their parents.

In general, this data indicate that probands and consultands endeavour to disseminate information about the diagnosis of a genetic condition to their family members over time. However, there are a number of indicators arising from this study, demonstrating that families may benefit from greater support from genetics services to satisfactorily grasp the genetic information and facilitate subsequent communication. For instance, genetic health professionals discussing at-risk family members and encouraging communication at the time of diagnosis may not be appropriately addressing families' needs. The data suggest that probands and consultands are focused on their health or the health of the diagnosed individual (usually their child) and not out towards at-risk family members. Genetic counselling involving a trauma or crisis counselling model $^{34}$ may be more appropriate at this stage to allow individuals a supportive 'holding' space $^{34}$ and time to come to terms with a change in expected health and often reproductive implications for themselves or their children. Crisis counselling, a focused, short-term, specialised approach, aims to address the needs of individuals and their families after a traumatic experience such as the diagnosis of a genetic condition. This model draws on individuals' strengths and available supports to assist with coping and alleviate immediate concerns while tying in with the individuals' medical needs. ${ }^{34}$ Delaying discussions about the dissemination of genetic information to at-risk family members to a later stage may be appropriate to allow probands and consultands time to reconcile with the trauma of the diagnosis.

This study illustrates how probands and consultands commonly report a period of searching for more information about the genetic condition; that communication in families is a process that takes place over time; and that probands and consultands have concerns about their family members' awareness and understanding of the genetic condition. The provision of dedicated follow-up for probands and consultands would provide the opportunity for genetic health professionals to support and meet needs regarding further education about the genetic condition, and also in clarifying which family members are at-risk, together with counselling and support about communication.
Current practice in most genetics services involves contact with the proband and/or consultand until the diagnosis is determined. ${ }^{35}$ The provision of follow-up is minimal so the genetic health professionals have to counsel, educate and encourage communication within a limited time period. The exception is the method of direct contact from the genetics service to at-risk family members by posting generic letters warning of increased risk of cancer. ${ }^{36}$ Although this method of direct contact results in a significantly increased uptake of clarification of genetic status by at-risk family members, ${ }^{36}$ other research suggests that probands and consultands prefer to disseminate genetic information to family members rather than relying on the genetics service. ${ }^{21} \mathrm{~A}$ follow-up consultation where familial communication issues are addressed seems a logical and practical method given the results from these interviews.

The limitations of the results drawn from this research stem from the number of interviews and potential bias of participants who were willing to be involved. The recruitment of research participants is difficult, and there is concern that those who did not reply may have had different experiences when trying to communicate information to their family members. The barriers and facilitators to family communication may also have influenced the recruitment of participants for the interviews with family members. Communication often occurs more frequently to first-degree family members, ${ }^{6,7}$ which may be the reason that all participants in the family member interviews were firstdegree relatives of the proband or consultand. Nevertheless, there is a lack of published research involving families affected with genetic conditions that are not familial cancer syndromes. This exploratory study contributes findings with implications for general genetic practice to the currently available literature reporting on research related to communication of genetic information in families.

\section{Conclusion}

The process of communicating genetic information in families commences with the traumatic experience of a genetic diagnosis. Probands and consultands are often counselled about the diagnosis and implications for family members and encouraged to communicate the genetic information to at-risk family members. Participants in this study explained that communication did occur immediately after diagnosis, but their focus was on the health implications of the genetic condition for the proband and communication revolved around this and not the family members' risk status. Following the time of diagnosis, the proband or their parents (consultands) would search for more information about the genetic condition to improve their understanding and continue to inform family members, often using pre-existing familial patterns of communication. This may result in family members who 
were not very aware about the health and reproductive implications of the genetic condition. Therefore, to better support probands and consultands during the diagnosis and while communicating to at-risk family members, genetic services may consider utilising trauma or crisis counselling models around the time of diagnosis. At a later time, after the initial trauma of diagnosis, the provision of follow-up consultations would allow probands and consultands to have questions answered about the genetic condition, to receive up-to-date information and to discuss communicating genetic information to at-risk family members.

\section{Acknowledgements}

We thank the individuals who agreed to be involved in this study, the Australian Research Council for funding this project and the Murdoch Childrens Research Institute and Genetic Health Services Victoria for their ongoing support.

\section{References}

1 Forrest LE, Delatycki MB, Skene L, Aitken M: Communicating genetic information in families - a review of guidelines and position papers. Eur J Hum Genet 2007; 15: 612-618.

2 Sermijn E, Goelen G, Teugels E et al: The impact of proband mediated information dissemination in families with a BRCA1/2 gene mutation. J Med Genet 2004; 41: e23.

3 Wertz DC, Fletcher JC, Berg K in: (ed): Review of Ethical Issues in Medical Genetics. Geneva: World Health Organization, 2003.

4 Sudell A: To tell or not to tell: the scope of physician-patient confidentiality when relatives are at risk of genetic disease. J Contemp Health Law Policy 2001; 18: 273-295.

5 Australian Law Reform Commission and Australian Health Ethics Committee (ALRC/AHEC): Essentially yours: the protection of human genetic information in Australia. Sydney: Australian Law Reform Commission, 2003. (Report No. 96).

6 Claes E, Evers-Kiebooms G, Boogaerts A, Decruyenaere M, Denayer L, Legius E: Communication with close and distant relatives in the context of genetic testing for hereditary breast and ovarian cancer in cancer patients. Am J Med Genet A 2003; 116A: 11-19.

7 Daly MB, Itzen M, Costalas JW, Balshem A: The communication of BRCA1 and BRCA2 test results to at risk relatives. Breast Cancer Res Treat 1997; 46: 38.

8 d'Agincourt-Canning L: Experiences of genetic risk: disclosure and the gendering of responsibility. Bioethics 2001; 15: 231-247.

9 Denayer L, De Boeck K, Evers-Kiebooms G, Van den Berghe H: The transfer of information about genetic transmission to brothers and sisters of parents with a CF-child. Birth Defects Orig Artic Ser 1992; 28: 149-158

10 Julian-Reynier C, Eisinger F, Chabal F et al: Disclosure to the family of breast/ovarian cancer genetic test results: patient's willingness and associated factors. Am J Med Genet 2000; 94: 13-18.

11 Kenen R, Ardern-Jones A, Eeles R: We are talking, but are they listening? Communication patterns in families with a history of breast/ovarian cancer (HBOC). Psychooncology 2004; 13: 335-345.

12 Sorenson JR, Jennings-Grant T, Newman J: Communication about carrier testing within hemophilia A families. Am J Med Genet C Semin Med Genet 2003; 119C: 3-10.

13 Ormond KE, Mills PL, Lester LA, Ross LF: Effect of family history on disclosure patterns of cystic fibrosis carrier status. Am J Med Genet C Semin Med Genet 2003; 119C: 70-77.

14 Lehmann LS, Weeks JC, Klar N, Biener L, Garber JE: Disclosure of familial genetic information: perceptions of the duty to inform. Am J Med 2000; 109: 705-711.
15 Gaff CL, Clarke AJ, Atkinson P et al: Process and outcome in communication of genetic information within families: a systematic review. Eur J Hum Genet 2007; 15: 999-1011.

16 Galvin KM, Brommel BJ: Family Communication: Cohesion and Change, 5th edn. New York: Addison-Wesley Longman Inc, 1999.

17 Minuchin S: Families and Family Therapy. Cambridge, MA: Harvard University Press, 1974.

18 Landsbergen K, Verhaak C, Kraaimaat F, Hoogerbrugge N: Genetic uptake in BRCA-mutation families is related to emotional and behavioral communication characteristics of index patients. Fam Cancer 2005; 4: 115-119.

19 Lewis S, Curnow L, Ross M, Massie J: Parental attitudes to the identification of their infants as carriers of cystic fibrosis by newborn screening. J Paediatr Child Health 2006; 42: 533-537.

20 McGivern B, Everett J, Yager GG, Baumiller RC, Hafertepen A, Saal HM: Family communication about positive BRCA1 and BRCA2 genetic test results. Genet Med 2004; 6: 503-509.

21 Forrest K, Simpson SA, Wilson BJ et al: To tell or not to tell: barriers and facilitators in family communication about genetic risk. Clin Genet 2003; 64: 317-326.

22 Fanos JH, Johnson JP: Barriers to carrier testing for adult cystic fibrosis sibs: the importance of not knowing. Am J Med Genet 1995; 59: 85-91.

23 Forrest Keenan K, Simpson SA, Wilson BJ et al: It's their blood not mine': who's responsible for (not) telling relatives about genetic risk? Health Risk Soc 2005; 7: 209-226.

24 MacDonald DJ, Sarna L, van Servellen G, Bastani R, Giger JN, Weitzel JN: Selection of family members for communication of cancer risk and barriers to this communication before and after genetic cancer risk assessment. Genet Med 2007; 9: 275-282.

25 Strauss A, Corbin J: Basic of Qualitative Research: Grounded Theory Procedures and Techniques. London: Sage, 1990.

26 Liamputtong P, Ezzy D: Making sense of qualitative data: analysis process; in: Liamputtong P, Ezzy D (eds): Qualitative Research Methods, 2nd edn. South Melbourne: Oxford University Press, 2005, pp 257-285.

27 Talarico JM, Rubin DC: Flashbulb memories are special after all; in phenomenology, not accuracy. Appl Cogn Psychol 2007; 21: 557-578.

28 Hill V, Sahhar A, Aitken M, Savarirayan R, Metcalfe S: Experiences at the time of diagnosis of parents who have a child with a bone dysplasia resulting in short stature. Am J Med Genet A 2003; 122A: 100-107.

29 Dent KM, Carey JC: Breaking difficult news in a newborn setting: Down syndrome as a paradigm. Am J Med Genet C Semin Med Genet 2006; 142C: $173-179$.

30 Ablon J: Parents' responses to their child's diagnosis of neurofibromatosis 1. Am J Med Genet 2000; 93: 136-142.

31 Hughes C, Lerman C, Schwartz $M$ et al: All in the family: evaluation of the process and content of sisters' communication about BRCA1 and BRCA2 genetic test results. Am J Med Genet 2002; 107: $143-150$.

32 Raupach JCA, Hiller JE: Information and support for women following the primary treatment of breast cancer. Health Expect 2002; 5: 289-301.

33 Skinner D, Schaffer R: Families and genetic diagnoses in the genomic and Internet age. Infants Young Child 2006; 19: 16-24.

34 Koocher GP, Pollin I: Medical crisis counseling: a new service delivery model. J Clin Psychol Med Settings 1994; 1: 291-299.

35 Wright C, Kerzin-Storrar L, Williamson PR et al: Comparison of genetic services with and without genetic registers: knowledge, adjustment, and attitudes about genetic counselling among probands referred to three genetic clinics. J Med Genet 2002; 39: 84e.

36 Suthers GK, Armstrong J, McCormack J, Trott D: Letting the family know: balancing ethics and effectiveness when notifying relatives about genetic testing for a familial disorder. J Med Genet 2006; 43: 665-670. 